\title{
Capability curve analysis of photovoltaic generation systems
}

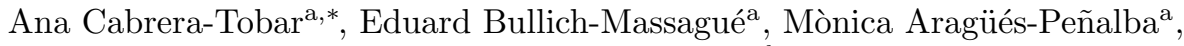 \\ Oriol Gomis-Bellmunt ${ }^{\mathrm{a}, \mathrm{b}}$ \\ ${ }^{a}$ Centre d'Innovació Tecnològica en Convertidors Estàtics $i$ Accionamients \\ (CITCEA-UPC), Department d'Enginyeria Elèctrica, Universitat Politècnica de Catalunya, \\ UPC. Av. Diagonal 647, Pl. 2. 08028, Barcelona, Spain \\ ${ }^{b}$ Catalonia Institute for Energy Research, IREC, Jardins de les Dones de \\ Negre,1,Pl.2a,08930 Sant Adrià del Besòs,Spain
}

\begin{abstract}
The present article assesses the study of the PV generator capability curves for use in large scale photovoltaic power plants (LS-PVPPs). For this purpose, the article focuses on three main aspects: (i) the modelling of the main components of the PV generator, (ii) the operational limits analysis of the PV array together with the inverter, and (iii) the capability curve analysis considering variable solar irradiance and temperature. To validate this study a PVPP of 1MW is designed, modelled and simulated in DIgSILENT PowerFactory ${ }^{\circledR}$. The results for each case scenario shows that the capability curve and the limitations are directly affected by: the solar irradiance, temperature, dc voltage, and the modulation index.

Keywords: Photovoltaic Power Plants, Capability curves, PQ characteristics, $\mathrm{PV}$ inverters.
\end{abstract}

\section{Nomenclature}

$\eta \quad \mathrm{PV}$ inverter efficiency

G $\quad$ solar irradiance $\left(\mathrm{W} / \mathrm{m}^{2}\right)$

\footnotetext{
${ }^{*}$ Corresponding author

Email address: ana.cabrera@citcea.upc.edu (Ana Cabrera-Tobar)
} 


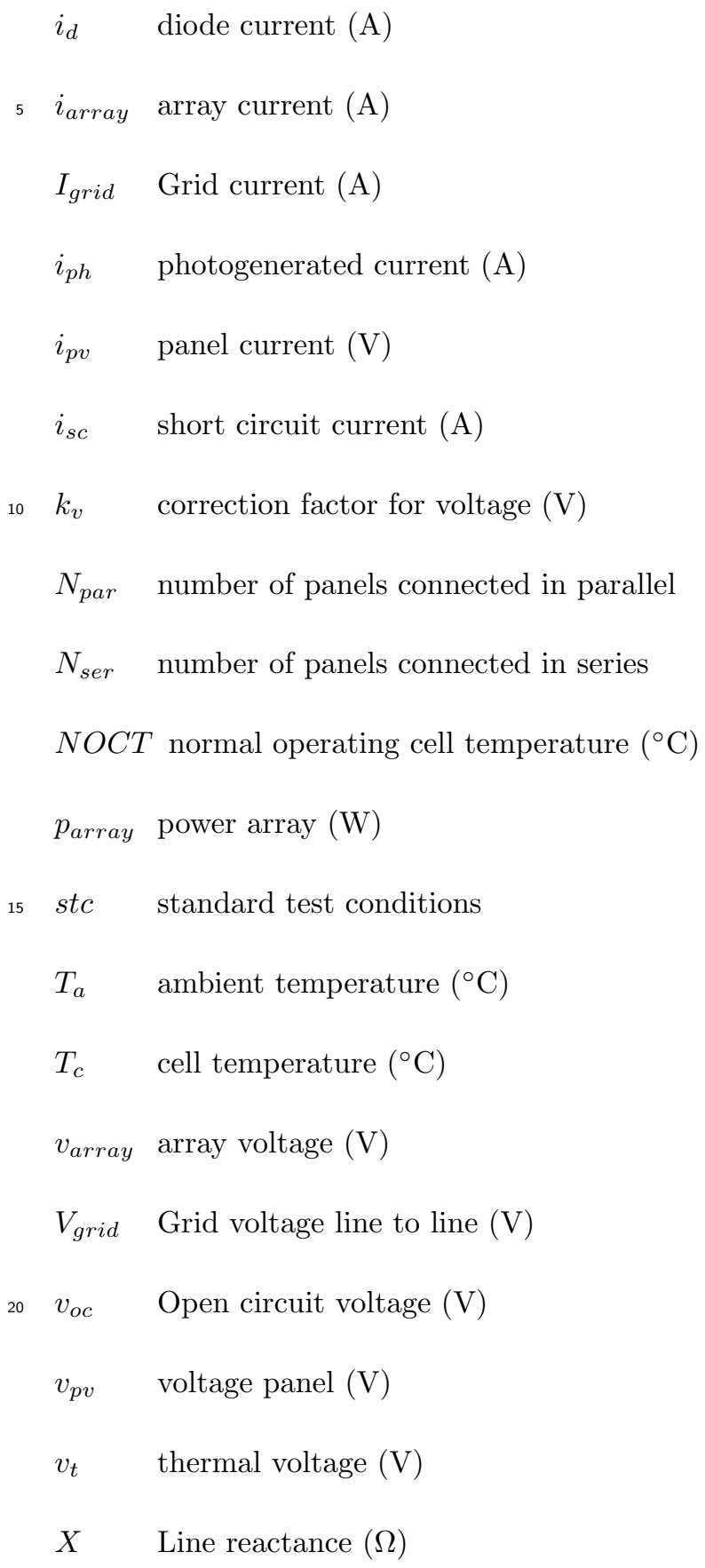




\section{Introduction} Africa and Romania have specific grid codes for large scale photovoltaic power plants (LS-PVPPs) requiring their participation in the ancillary services as conventional power plants [1]. The intermittent solar irradiation and the cloud cover means that LS-PVPPs can struggle to comply with these grid codes. The current technology used could enhance the performance of these PVPPs to comply the different requirements.

For this new application, PV inverters have been progressively introduced to provide ancillary services. However, there is still no deep study on the inverter limits considering the power production, and little research has been developed.

35 For instance, there is a study of how wind farms and PV power plants can provide ancillary services by Ellis and et al. [2]. This study summarizes the main characteristics of the current technology used in wind farms and PV power plants. The study also focuses on a critical review of the grid code requirements giving an insight of possible improvements considering the intermittent reactive power limits of inverters used by small PV system. In this study, the converter has two stages: a dc-dc converter and then a dc-ac converter. The analysis is developed with this type of unit for a single PV panel where the dcdc converter has the task of stepping up the voltage and to work at maximum power point. Because it is a small system, the variation of the dc voltage is not considered. It also does not consider the pulse modulation factor. Another study was developed by F.Delfino and et al. [4], that obtains the capability curve for a PV generator (PV panel and inverter). The analysis considers the variation of the modulation index but assumes that the dc voltage is constant.

In both studies, the implication of solar irradiance or temperature has not been

considered in the control or in the analysis. Besides, the voltage considered in both studies is equal to the value that permits the PV generator to operate at maximum power point (MPP). 


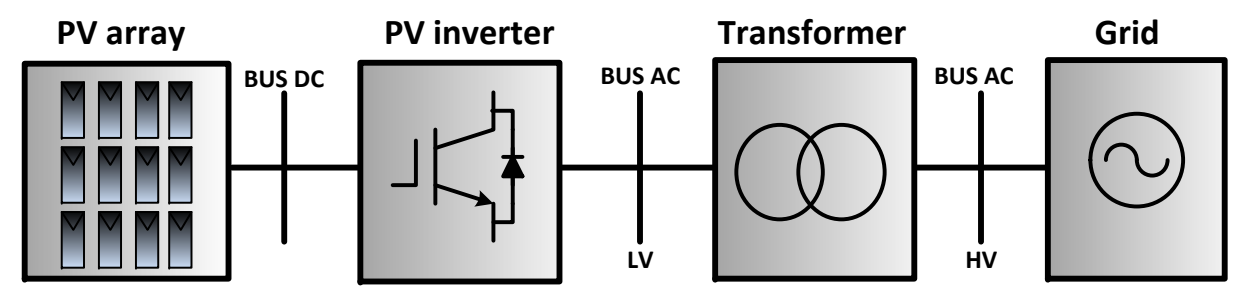

Figure 1: Components of a PV generator interconnected with the grid

Accordingly, the aim of the current paper is the analysis of the PV inverter

55 capability curves taking into account the solar irradiance, the ambient temperature, the dc voltage variation and the inverter operation. For this purpose, this paper is structured as follows: Section 2 explains the mathematical model of the PV generator. Section 3 presents the mathematical analysis and the capability curves of the PV generator. Section 4 presents the influence of ambient conditions and the inverter operation on the capability curves. The validation of the mathematical analysis is developed in Section 5 Finally, the conclusions are drawn in Section 6 .

\section{PV generator model}

The PV generator consists of a PV array interconnected with a single PV inverter and a transformer (Figure 1) in which the different components are connected in central configuration [5]. To develop the mathematical model of the PV generator, the analysis is divided into two parts: (i) PV array model and (ii) the PV inverter together with the transformer model.

\subsection{PV array model}

70

The PV array model is based on the general model of the PV solar cell (Figure 2 that depends on solar irradiance, temperature and the dc voltage [6], [7. To calculate the output characteristics of the PV panel, it is necessary to consider the open circuit voltage $\left(V_{o c}\right)$ and the short circuit current $\left(I_{s c}\right)$ 


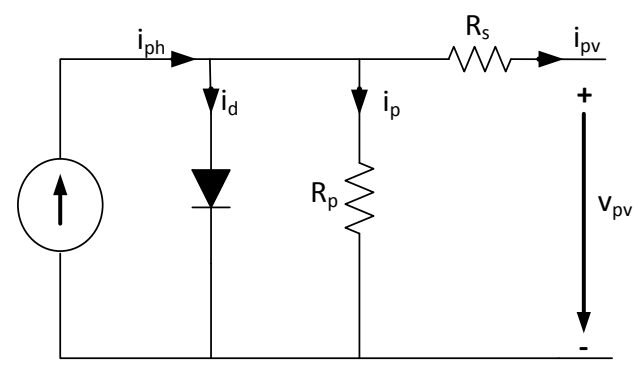

Figure 2: Simplified model of the PV cell

at standard test conditions (stc) that are usually available in PV panels data sheets.

These values of voltage and current change when the irradiance or the temperature differ from the standard conditions ( $G=1000 \mathrm{~W} / \mathrm{m}^{2}$ and a $T_{a}=25$ ${ }^{\circ} \mathrm{C}$ ). In this case, the new solar cell temperature $\left(T_{c}\right)$ (equation 1 affects the $v_{t}$ and the $v_{o c}$. These new values are calculated in equations 2 and 3 .

80

$$
\begin{gathered}
T_{c}=T_{a}+G \cdot \frac{N O C T-20}{800} \\
v_{t}=v_{t_{s t c}} \cdot \frac{T_{c}}{T_{s t c}} \\
v_{o c}=v_{o c_{s t c}}+k_{v} \cdot\left(T_{c}-25\right)
\end{gathered}
$$

As the current mainly depends on the irradiance, the short circuit current and the photogenerated current are written in equations (4) and (5) for a so-

lar irradiance higher than $200 \mathrm{~W} / \mathrm{m}^{2}$. For lower irradiance, the equations are expressed in (6) and (7) as it is explained in [8].

$$
\begin{gathered}
i_{p h} \approx i_{p h_{s t c}} \cdot \frac{G}{G_{s t c}} \\
i_{s c} \approx i_{s c_{s t c}} \cdot \frac{G}{G_{s t c}} \\
i_{p h} \approx i_{p h_{s t c}} \cdot 0.008 \cdot \frac{G^{2}}{G_{s t c}} \\
i_{s c} \approx i_{s c_{s t c}} \cdot 0.008 \cdot \frac{G^{2}}{G_{s t c}}
\end{gathered}
$$


The new total current $\left(i_{p v}\right)$ of the PV panel is calculated considering the new values of current at any ambient condition and the dc voltage (equation 8).

$$
i_{p v}=\frac{i_{p h}-i_{d}-\frac{v_{p v}}{R p}}{1+\frac{R s}{R p}}
$$

Finally, the current and voltage values of the PV array are written in equations 9 and 10 and depend on the number of PV panels interconnected in series and parallel. The total power is calculated as equation (11) shows.

$$
\begin{gathered}
i_{\text {array }}=i_{p v} \cdot N_{\text {par }} \\
v_{\text {array }}=v_{p v} \cdot N_{\text {ser }} \\
p_{\text {array }}=i_{\text {array }} \cdot v_{\text {array }}
\end{gathered}
$$

\section{2. $P V$ inverter and transformer model}

The PV inverter under analysis is a VSC converter that exchanges power from the PV array (DC side) to the grid (AC side). This inverter has two IGBT per branch and one inductor per line as a filter. Furthermore, the transformer is modelled as an inductor. In this case, the filter and the transformer inductance are represented by $\left(L_{f}\right)$. The grid is modelled as three voltage sources with their corresponding inductance $\left(L_{g}\right)$ and the total resistance is neglected (Figure 3 ).

The conversion from dc to ac developed by the inverter uses a modulation technique that permits an ac current as similar as possible to a sinusoidal wave form. For the current analysis sinusoidal PWM technique (SPWM) is considered, in which the output line to line voltage $\left(V_{a^{\prime} b^{\prime}}\right)$ depends on the dc voltage from the dc bus $\left(V_{D C}=v_{\text {array }}\right)$ and a modulation index $(\mathrm{M})$ (Figure 4). The relationship between the ac and the dc voltage is linear if the modulation index varies between 0 to 1 as equation 12 shows. However, after this value, the relationship is not linear and the power quality of the sinewave is reduced. 


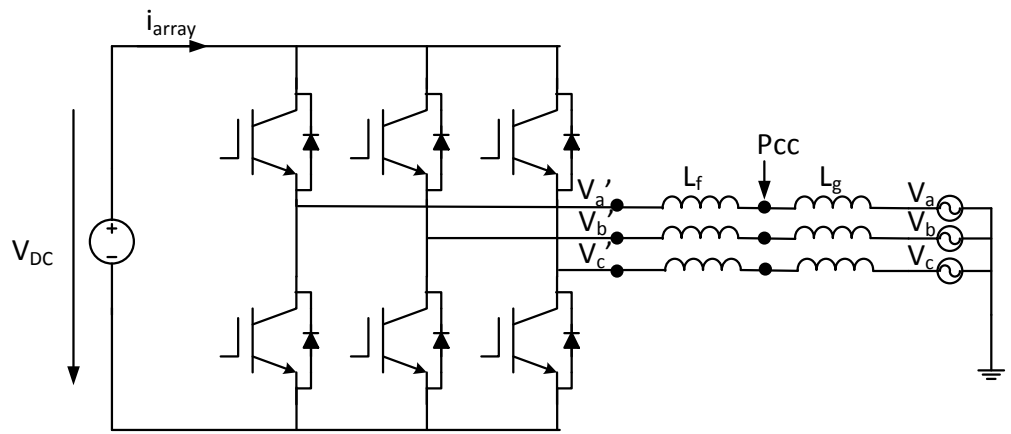

Figure 3: PV inverter interconnected with the grid

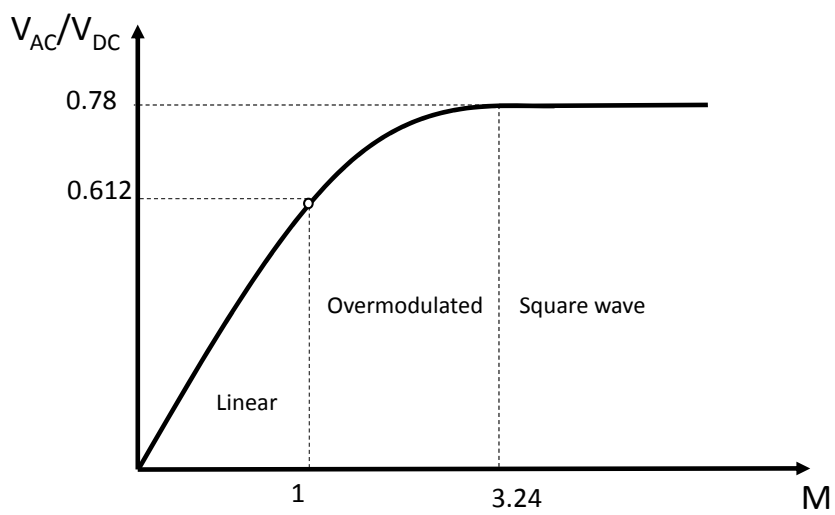

Figure 4: Output voltage and dc voltage in relation with Modulation index

$$
V_{a^{\prime} b^{\prime}}=M \cdot \frac{\sqrt{3} \cdot V_{D C}}{2 \sqrt{2}} \quad 0 \leq M \leq 1
$$
and the limitations of the PV generator are analysed in the following section.

\section{Capability curves of the PV generator}

To analyse the capability curves of the PV generator it is necessary to understand the limitations of voltage, current and power of each component. This 
section presents the equations that represents the limitations of the PV generator related to the transfer of active and reactive power at the point of common coupling (PCC).

\subsection{Voltage limitation}

The dc voltage can vary from 0 to the maximum possible in order to extract different values of power from the PV array. However, the inverter sets the limitations of the de voltage due to its operation. The minimum de voltage $\left(v_{\min }\right)$ accepted by the inverter that will allow the ac voltage to be inside the values permitted by the grid codes is calculated in equation (13). In this equation the maximum modulation index is considered $(M=1)$.

$$
v_{\min }=\frac{2 \sqrt{2}}{\sqrt{3}} \cdot \frac{V_{a^{\prime} b^{\prime}}}{1}
$$

In the case that the PV inverter is working at MPP, the minimum solar irradiance accepted to keep the voltage higher than the minimum value is calculated as:

$$
G_{\text {min }}=\left(\frac{v_{d c_{\text {min }}}-v_{o c_{s t c}}}{k_{v}}+25-T_{a}\right) \times \frac{800}{N O C T-20}
$$

Besides the minimum voltage, the maximum dc voltage $v_{\max }$ must also be determined. This value depends on the open circuit voltage of each panel times the number of panels connected in series (Equation 16). If the dc voltage is higher than the maximum of the PV array, the power supplied will be zero. The maximum $V_{o c}$ of the $\mathrm{PV}$ array is dependent on the minimum temperature possible at the location chosen. These voltage limitations are written as:

$$
\begin{gathered}
v_{o c_{\max }}=v_{o c_{s t c}}+k_{v} \cdot\left(T_{a_{\min }}+G_{\min } \cdot \frac{N O C T-20}{800}-25\right) \\
v_{\max }=v_{o c_{\max }} \cdot N \text { ser }
\end{gathered}
$$




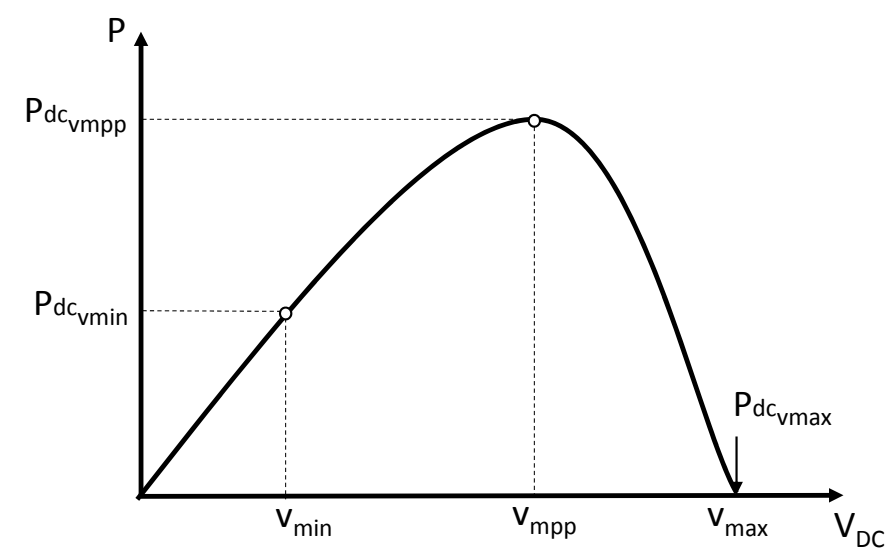

Figure 5: Power vs Voltage at the dc side. Main power points to analyse

140

\subsection{Current limitation}

The limitations of the DC current of the PV array depend specifically on the solar panel characteristics and the solar irradiance. The temperature does not play an important role in the variation of the current and thus this factor is not considered. The maximum current depends on the maximum solar irradiance and the $i_{s c}$ value at standard conditions as:

$$
i_{d c_{\max }}=i s c_{s t c} \cdot \frac{G_{\max }}{G_{s t c}} \cdot N p a r
$$

The PV inverter current at the dc side should handle the current of the PV array at the highest irradiance. This current and the voltage determine the inverter operation area at the dc side.

\subsection{Active power limitation}

The PV curve of the PV array illustrated in Figure 5 shows the behaviour of power vs the dc voltage. Three important points are necessary to analyse as: (i) $P_{d c_{v m i n}}$, (ii) $P_{d c_{v m p p}}$ and (iii) $P_{d c_{v \max }}$. The minimum value of Power $\left(P_{d c_{v \text { min }}}\right)$, at the left side of the curve, considers the minimum dc voltage possible and the current at any ambient condition. In this case, if the solar radiation is too low, the current will be close to 0 and the PV array will not be supplying 
enough active power to the grid. The maximum power $\left(P_{d c_{v m p p}}\right)$ is obtained when the dc voltage is equal to the value of $v_{m p p}$ for each solar irradiance and the corresponding temperature. The final point of power $P_{d c_{v \max }}$ is when the dc voltage is equal to the open circuit voltage that depends specially on the temperature. For any solar irradiance and temperature, the values of $P_{d c_{v m i n}}$, $P_{d c_{v m p p}}$ and $P_{d c_{v \max }}$ are defined as:

$$
\begin{gathered}
P_{d c_{v \min }}\left(G, T_{a}\right)=v_{\min } \cdot I_{d c}\left(G, T_{a}\right) \\
P_{d c_{v m p p}}\left(G, T_{a}\right)=V_{m p p}\left(G, T_{a}\right) \cdot I_{d c}\left(G, T_{a}\right) \\
P_{d c_{v \max }}\left(G, T_{a}\right)=v_{\max }\left(G, T_{a}\right) \cdot I_{d c}\left(G, T_{a}\right)
\end{gathered}
$$

Considering these power variations due to the solar irradiance and temper-

ature, the maximum possible power $\left(P_{\max _{a r r a y}}\right)$ that can be extracted from the PV array is determined at the highest solar irradiance and the lowest temperature possible at the location of the PVPP (equation 21). With this limitation of power, the PV inverter should be designed for this active power taking into account an overrate of $25 \%$ (equation 22.

$$
\begin{gathered}
P_{\text {max }_{\text {array }}}\left(G_{\max }, T_{a_{\text {min }}}\right)=V_{\text {mpp }}\left(G_{\text {max }}, T_{a_{\text {min }}}\right) \cdot I_{d c}\left(G_{\text {max }}, T_{a_{\text {min }}}\right) \\
P_{\text {max }_{\text {inverter }}}=P_{\text {max }_{\text {array }}} \cdot 1.25
\end{gathered}
$$

From the analysis developed above, a safe operation area (S.O.A) is determined as illustrated in Figure 6.

\subsection{Reactive power limitations}

For this analysis, a simplified model of the PV inverter is used (Figure 7). From the model and the phasor diagram, illustrated in (Figure 8), the equations 175 of the active and the reactive power are:

$$
P=3 \frac{V_{\text {grid }} \cdot V_{\text {conv }}}{X} \cdot \sin (\delta)
$$




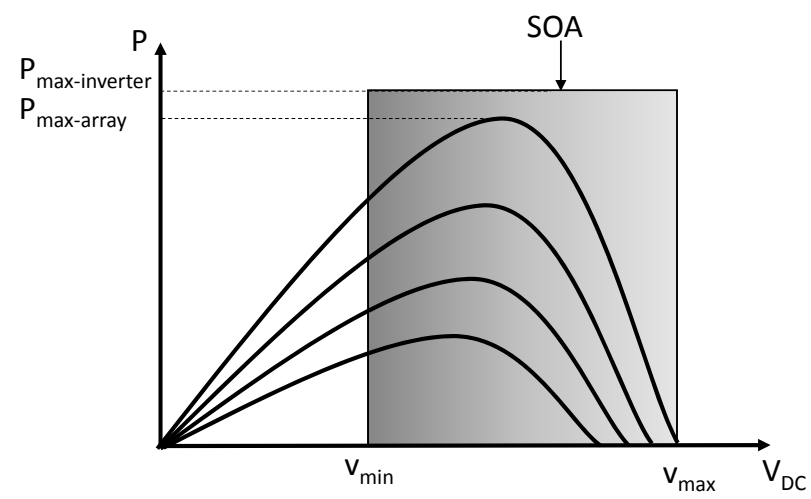

Figure 6: Safe operation area (SOA) of a PV generator

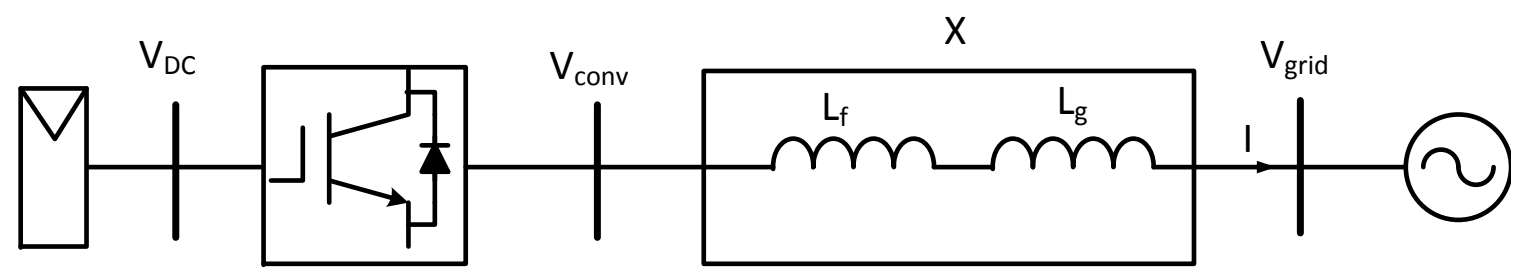

Figure 7: Simplified model of the Inverter

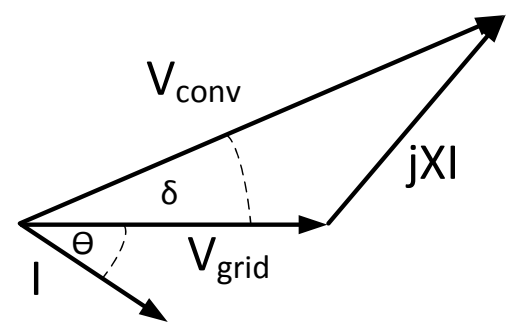

Figure 8: Phasor diagram of the PV inverter interconnected with the grid.

$$
Q=3 \frac{V_{\text {grid }}}{X}\left(V_{\text {conv }} \cos (\delta)-V_{\text {grid }}\right)
$$

The maximum apparent power that the PV generator can inject into the grid is given by the rated power of the inverter. Graphically, this limitation is illustrated as a circumference centred in the origin (Figure 9). The equations for these limitations are: 


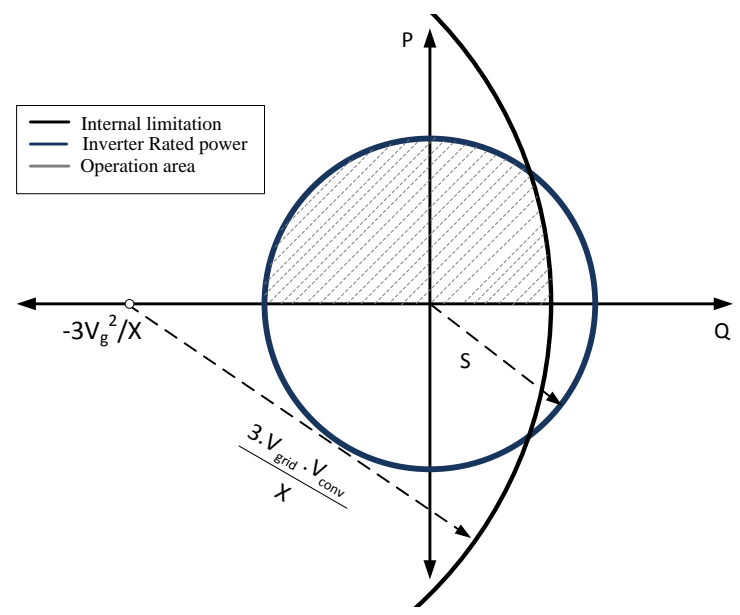

Figure 9: Basic PQ capability curve of the PV generator

$$
\begin{gathered}
S=\frac{3}{\sqrt{3}} \cdot V_{\text {grid }} \cdot I_{\text {grid }} \\
S^{2}=P^{2}+Q^{2}
\end{gathered}
$$

If $V_{g}$ rid is multiplied by each variable of the phasor diagram, a new equation is obtained:

$$
P^{2}+\left(Q+\frac{3 \cdot V_{\text {grid }}^{2}}{X}\right)^{2}=\left(3 \cdot \frac{V_{\text {grid }} \cdot V_{\text {conv }}}{X}\right)^{2}
$$

From this equation, the new curve is a circle that has a centre in $\frac{-3 V_{\text {grid }}^{2}}{X}$ in the $\mathrm{Q}$ axis with a radius of $\frac{3 \cdot V_{\text {grid }} \cdot V_{\text {conv }}}{X}$ (Figure 9). This curve represents the voltage limitation of the inverter. The radius of this curve varies due to the modulation index and the dc voltage. Also, the total reactance value at the PCC influences the final value for this radius. Drawing both equations together, the basic PQ capability of the converter is obtained and illustrated in Figure 9 


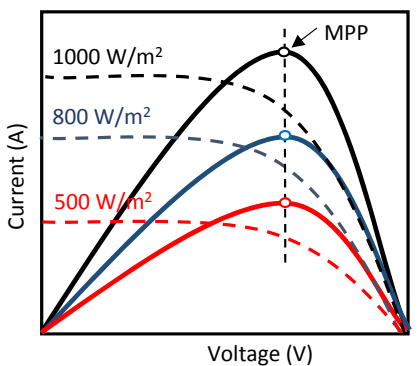

(a)

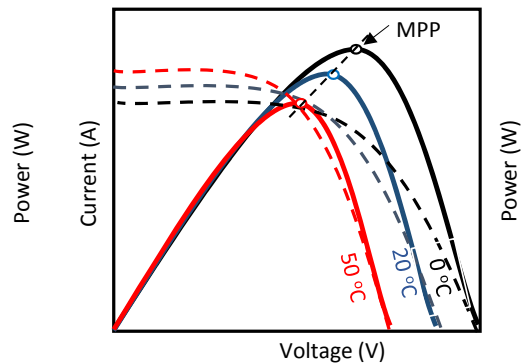

(b)

Figure 10: Characteristics of a PV array: (a) Different solar irradiance levels at $25^{\circ} \mathrm{C}$ and (b) Different ambient temperatures at $1000 \mathrm{~W} / \mathrm{m}^{2}$.

\section{Influence of ambient conditions}

In this section, the influence of ambient conditions on the limitations of active and reactive power is analysed considering the PV array and the PV inverter. According to the model of the PV array, its characteristic curves are illustrated in Figure 10 at different solar irradiance, temperature and dc voltage. It can be stated that the instantaneous value of power $\left(p_{\text {inst }}\right)$ and current depends on the instantaneous value of irradiance, temperature and dc voltage (equation 28).

$$
p_{\text {inst }}\left(G, T, V_{d c}\right)=i_{\text {array }}\left(G, T, v_{\text {array }}\right) \cdot v_{\text {array }}
$$

In the case that the PV inverter works at the MPP, then the dc voltage $\left(v_{m p p}\right)$ varies depending on the solar irradiance and temperature. Thus, the active power in this point has the following equation:

$$
p_{m p p}\left(G, T, v_{m p p}\right)=i_{\text {array }}\left(G, T, v_{m p p}(G, T)\right) \cdot v_{m p p}(G, T)
$$

Considering the equations for the dc power explained before and the inverter's efficiency $(\eta)$, the ac output power equations at the PCC are written in (30) and (31).

$$
p_{a c_{\text {inst }}}\left(G, T, V_{d c}\right)=I(G, T, V d c) \cdot v_{\text {array }} \cdot \eta\left(G, T, v_{\text {array }}\right)
$$




$$
P_{a c_{m p p}}\left(G, T, V_{d c}\right)=I_{m p p}(G, T) \cdot v_{m p p}(G, T) \cdot \eta\left(G, T, v_{m p p}\right)
$$

Depending on the ambient conditions, the active power that the PV gen-

205 erator can supply has two limitations. The first limitation corresponds to the highest solar irradiance, the minimum temperature of the plant location and the corresponding $v_{m p p}$. The second limitation corresponds to the maximum solar irradiance and the maximum temperature with the corresponding $v_{m p p}$. The difference between these values depend a lot on the difference of temperature that the geographical location has. These two limitations are formulated as:

$$
\begin{aligned}
& P_{a c_{\text {max }}}=P_{d c}\left(G_{\max }, T_{\min }, v_{\text {mpp }}\right) \cdot \eta\left(G_{\max }, T_{\min }, v_{\text {mpp }}\right) \\
& P_{a c_{\max 2}}=P_{d c}\left(G_{\text {max }}, T_{\max }, v_{\text {mpp }}\right) \cdot \eta\left(G_{\max }, T_{\max }, v_{\text {mpp }}\right)
\end{aligned}
$$

The limitation of the reactive power is calculated considering the two circles that dominates the PQ capability curve. If the curve is dominated by $S^{2}=$ $P^{2}(G, T)+Q^{2}$, then the reactive power will depend on the active power variation that was defined in the previous equations. In the case the curve is dominated by the equation (27), then the limitation of the reactive power depends on the dc voltage and the modulation index as it is expressed in equation (34). Considering the variation of the dc voltage, the reactive power can be written as 35 or 36 .

220

$$
\begin{gathered}
Q=\frac{3 \sqrt{3}}{2 \sqrt{2}} \times \frac{V_{g r i d} \cdot V_{d c} \cdot M}{X} \\
Q_{\text {inst }}\left(G, T, V_{d c}\right)=\frac{3 \sqrt{3}}{2 \sqrt{2}} \cdot \frac{V_{\text {grid }} \cdot v_{\text {array }} \cdot M}{X}
\end{gathered}
$$

The modulation index varies depending on the dc voltage value, meaning that the reactive power remains almost constant. In order to manage the reactive power, $\mathrm{M}$ can be imposed. This affects the ac voltage value of the converter, 
thus $\mathrm{M}$ only can vary between two permitted values: $M_{\min }$ and $M_{\max }$. These values depend on the ac voltage dead band set by the grid codes. For instance, Romania, Germany, South Africa and China have the same deadband of $\pm 10 \%$. Considering the dc voltage equal to $v_{m p p}$ for a single value of solar irradiance and temperature with an imposed $\mathrm{M}$, the minimum and the maximum reactive power are defined as:

$$
\begin{aligned}
Q_{\text {min }} & =\frac{3 \sqrt{3}}{2 \sqrt{2}} \cdot \frac{V_{\text {grid }} \cdot v_{\text {mpp }}(G, T) \cdot M_{\text {min }}}{X} \\
Q_{\text {max }} & =\frac{3 \sqrt{3}}{2 \sqrt{2}} \cdot \frac{V_{\text {grid }} \cdot v_{\text {mpp }}(G, T) \cdot M_{\text {max }}}{X}
\end{aligned}
$$

With the analysis developed previously, some interesting capability curves are obtained. For a variable dc voltage, the PQ curve that is obtained is shown in Figure 11. In the case that the dc voltage is equal to $v_{m p p}$, the PQ capability curve is illustrated in Figure 12. Finally, Figure 13 illustrates the PQ curve when the dc voltage is equal to $v_{m p p}$ and $\mathrm{M}$ is imposed to vary the reactive power.

\section{Validation of the system}

To validate the $\mathrm{PQ}$ capability curves obtained in the previous section, a PVPP of $1 \mathrm{MW}$ is designed, modelled and simulated in DiGSILENT Power-

${ }_{240}$ Factory ${ }^{\circledR}$. The PVPP has two PV generators of 0.5 MW each. The main characteristics of these PV generators are detailed in Table 1.

\begin{tabular}{lclc}
\hline PV panel characteristics & \multicolumn{2}{l}{ PV array characteristcs } \\
\hline $\mathrm{V}_{\text {oc }}$ & $58.8[\mathrm{~V}]$ & $\mathrm{P}_{\text {array }}$ & $0.5[\mathrm{MW}]$ \\
$\mathrm{I}_{\mathrm{sc}}$ & $5.01[\mathrm{~A}]$ & $\mathrm{N}_{\text {ser }}$ & 15 \\
$\mathrm{I}_{\mathrm{mpp}}$ & $4.68[\mathrm{~A}]$ & $\mathrm{N}_{\mathrm{par}}$ & 175 \\
$\mathrm{~V}_{\mathrm{mpp}}$ & $47[\mathrm{~V}]$ & $\mathrm{T}_{\min }, \mathrm{T}_{\max }$ & $0-70\left[{ }^{\circ} \mathrm{C}\right]$ \\
$k_{v}$ & $0.45\left[1 /{ }^{\circ} \mathrm{C}\right]$ & $\mathrm{G}_{\max }$ & $1100\left[\mathrm{~W} / \mathrm{m}^{2}\right]$ \\
\hline
\end{tabular}

Table 1: PV panel and array characteristics 


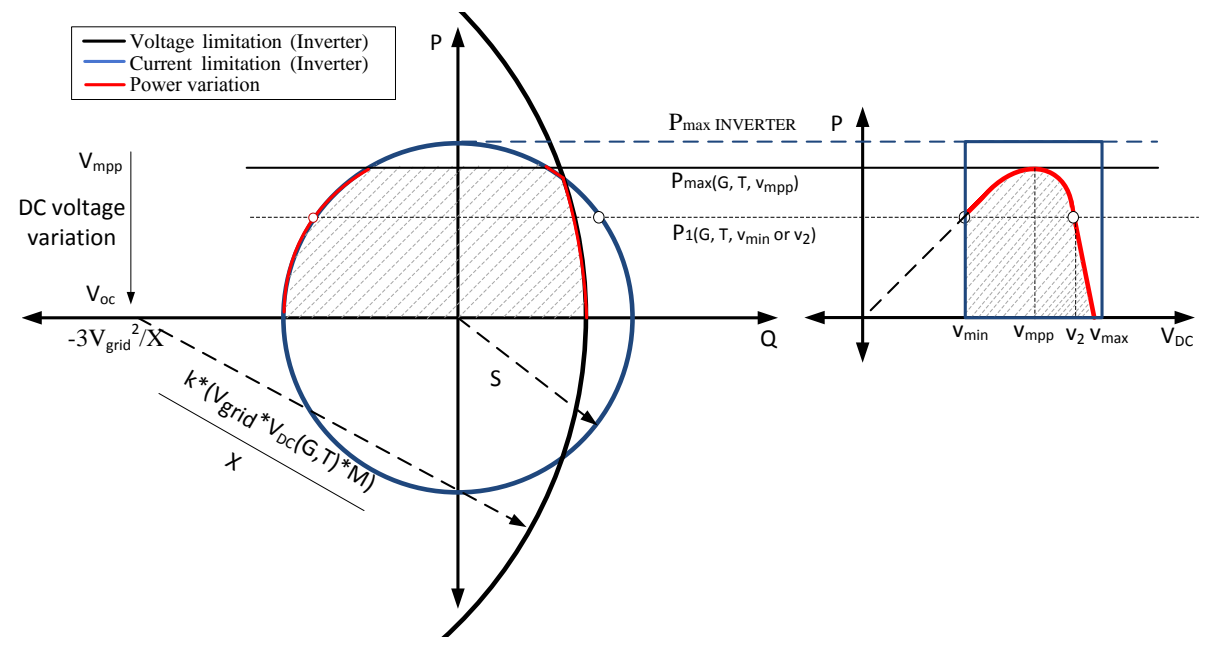

(a)

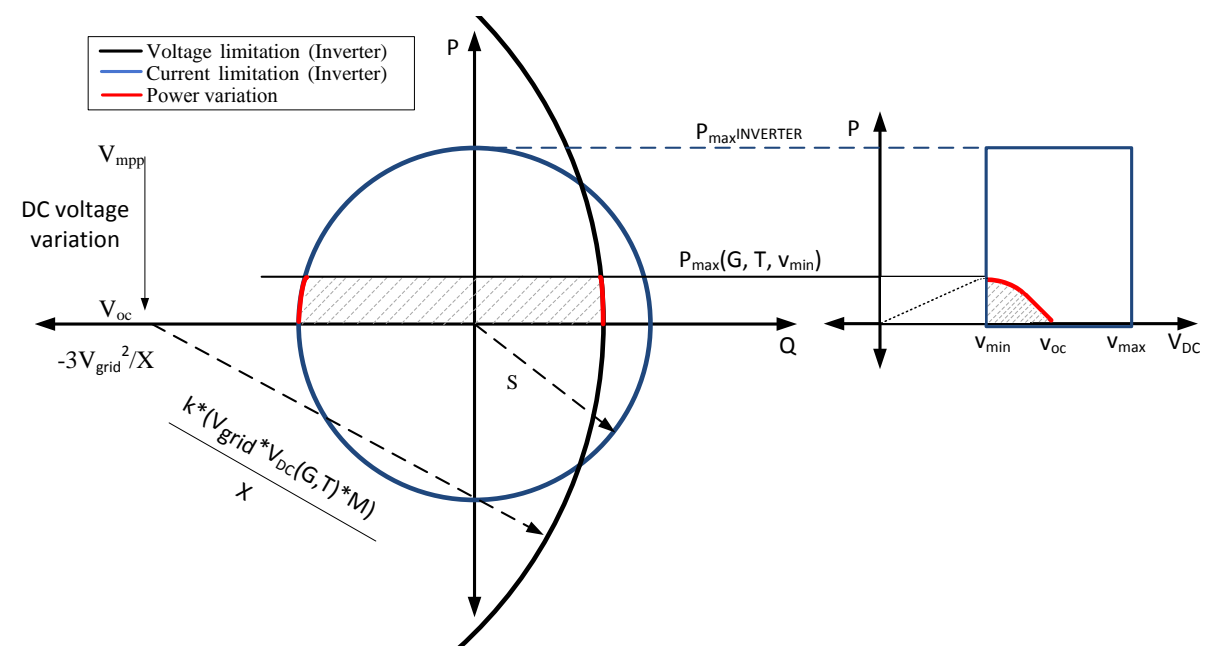

(b)

Figure 11: PQ capability curve of a PV generator for Vdc variable at maximum solar irradiance. (a) Minimum temperature (b) Maximum Temperature. 


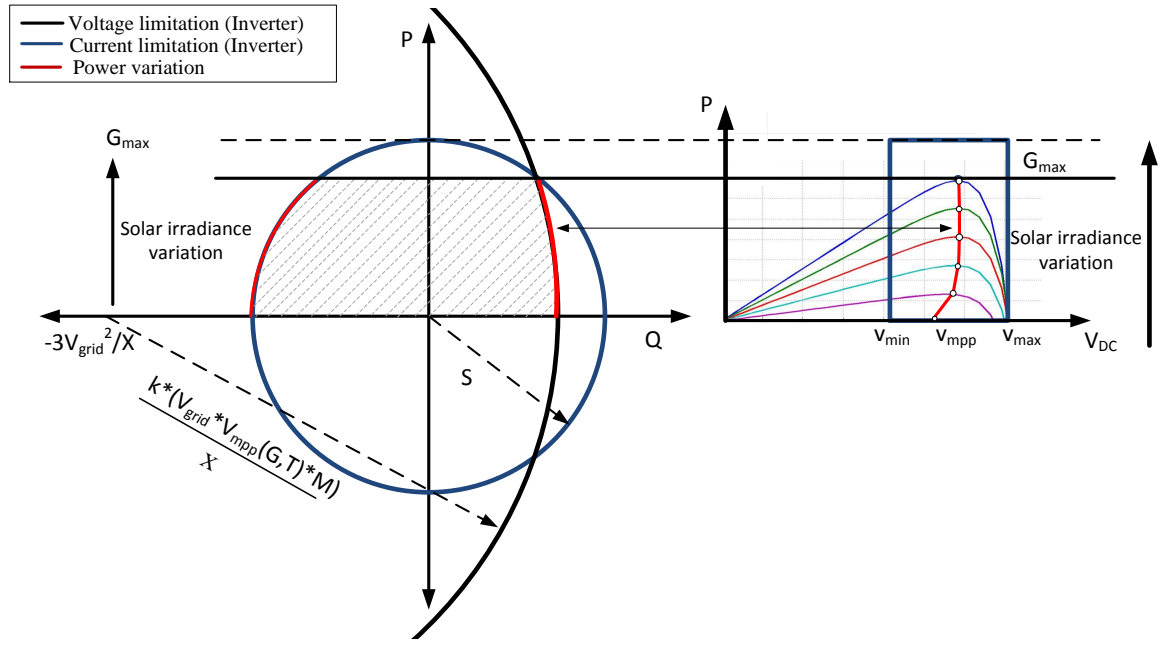

(a)

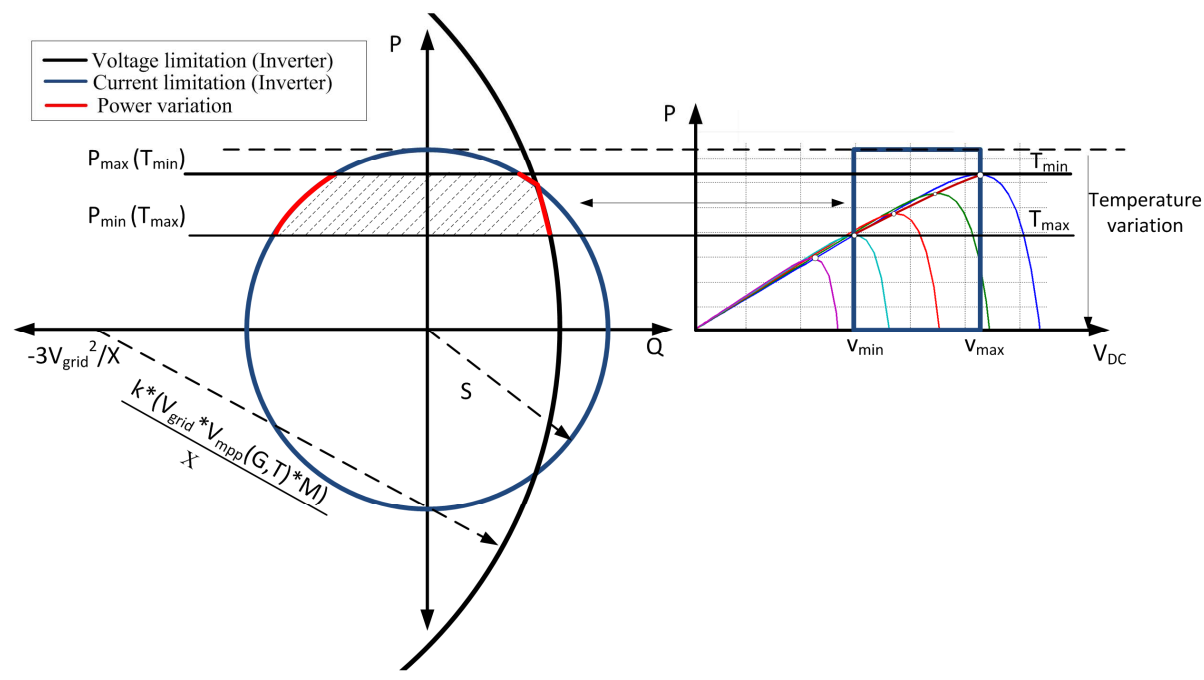

(b)

Figure 12: PQ capability analysis of the PV generator considering (a) Constant Temperature and variable solar irradiance (b) Constant solar irradiance and variable Temperature. 


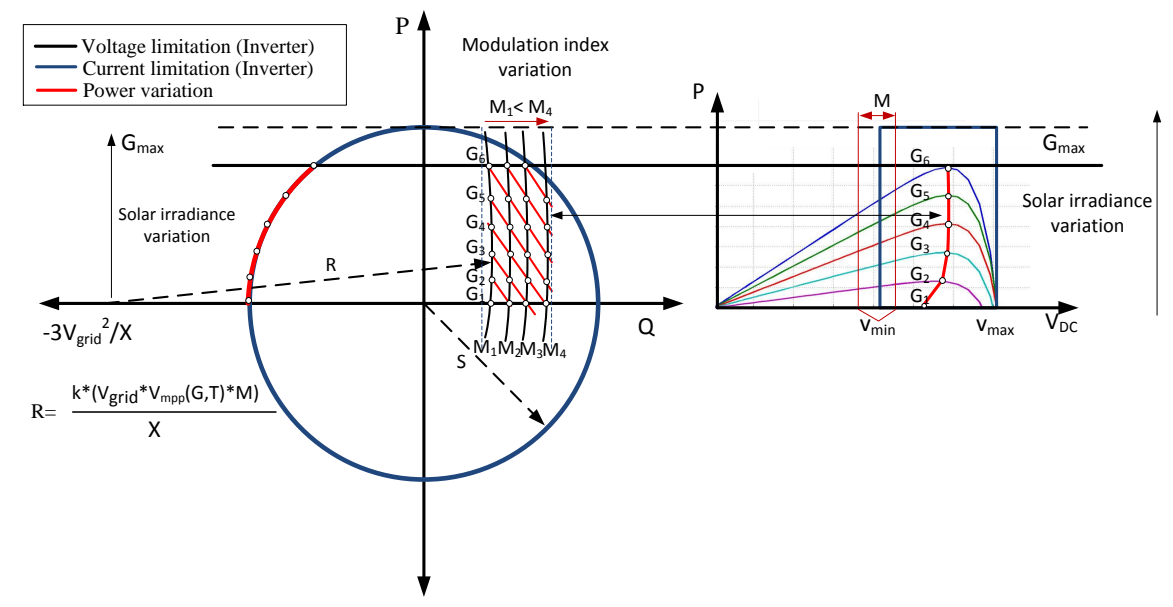

(a)

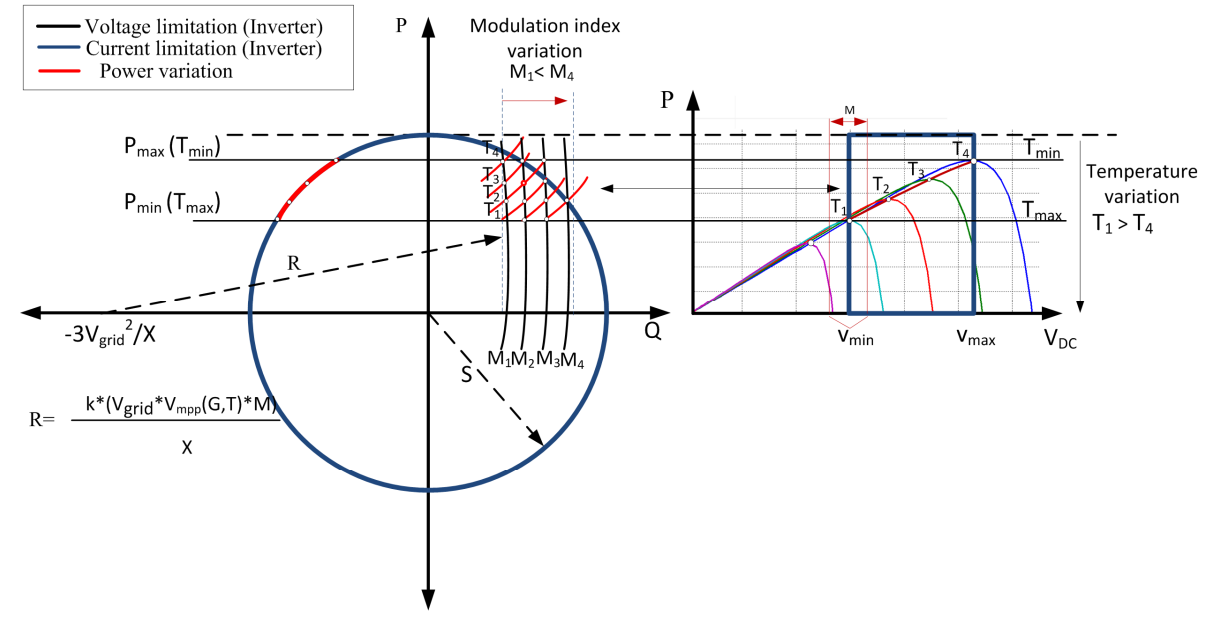

(b)

Figure 13: PQ capability curve of a PV generator for M variable. (a) Constant Temperature and variable solar irradiance (b) Constant solar irradiance and variable Temperature. 
The PVPP will work in underexcited or overexcited operation 17 . To test the PVPP under different solar radiation and temperature, three study cases are analysed: (a) Variation of dc voltage from $v_{\min }$ to $v_{\max }$, (b) Variation of the $v_{m p p}$ value, and (c) the variation of the modulation index.

\subsection{Variation of the dc voltage}

The PQ capability curve is analysed by the variation of the dc voltage under different ambient conditions. To understand the performance of the PV generator, two solar irradiance values are tested: 400 and $1000 \mathrm{~W} / \mathrm{m}^{2}$. Each solar irradiance is tested with three different temperature values: 10,20 and $40{ }^{\circ} \mathrm{C}$. The results are plotted in Figures 14 to 15

\subsection{Variation of $v_{m p p}$ value}

In this case the $v_{m p p}$ value varies according to the solar irradiance and temperature that permits extraction of the maximum active power for each ambient conditions. In this case, three scenarios are considered:

- Scenario 1: The solar irradiance will vary from 0 to $1000 \mathrm{~W} / \mathrm{m}^{2}$ with steps of $1 \mathrm{~W} / \mathrm{m}^{2}$. The ambient temperature is constant $\mathrm{T}=10{ }^{\circ} \mathrm{C}$.

- Scenario 2: The temperature will vary from 10 to $40{ }^{\circ} \mathrm{C}$ with steps of 0.1 ${ }^{\circ} \mathrm{C}$. The solar irradiance has a unique value of $1000 \mathrm{~W} / \mathrm{m}^{2}$.

- Scenario 3: The solar irradiance will vary from 0 to $1000 \mathrm{~W} / \mathrm{m}^{2}$ with steps of $1 \mathrm{~W} / \mathrm{m}^{2}$. The ambient temperature is constant $\mathrm{T}=40{ }^{\circ} \mathrm{C}$.

The PQ curve of the PVPP at the PCC, for each scenario, when the voltage is $v_{m p p}$, is illustrated in Figure 16 .

\footnotetext{
${ }^{1}$ Underexcited: absorbs reactive power. Overexcited: supplies reactive power. In both cases the PVPP supplies active power
} 


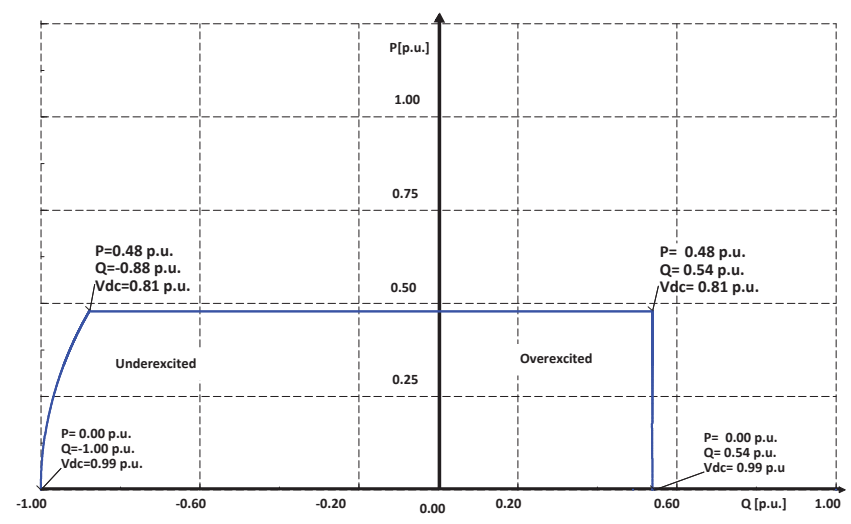

(a)

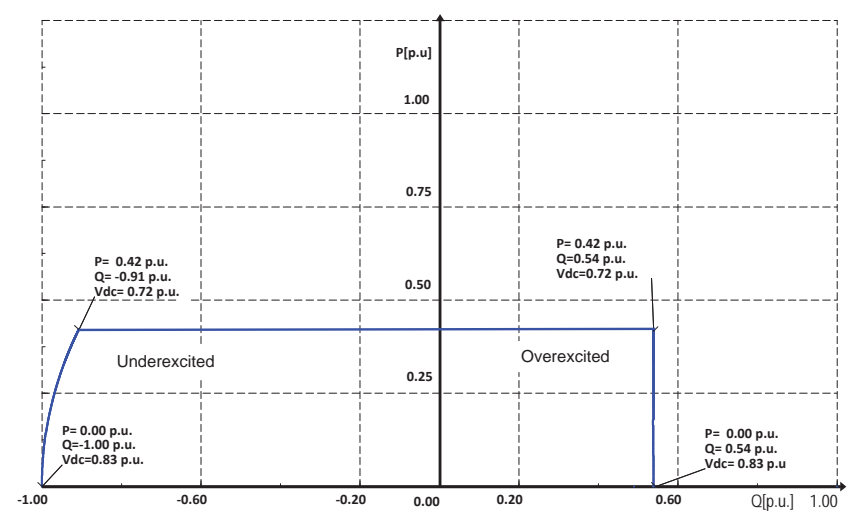

(b)

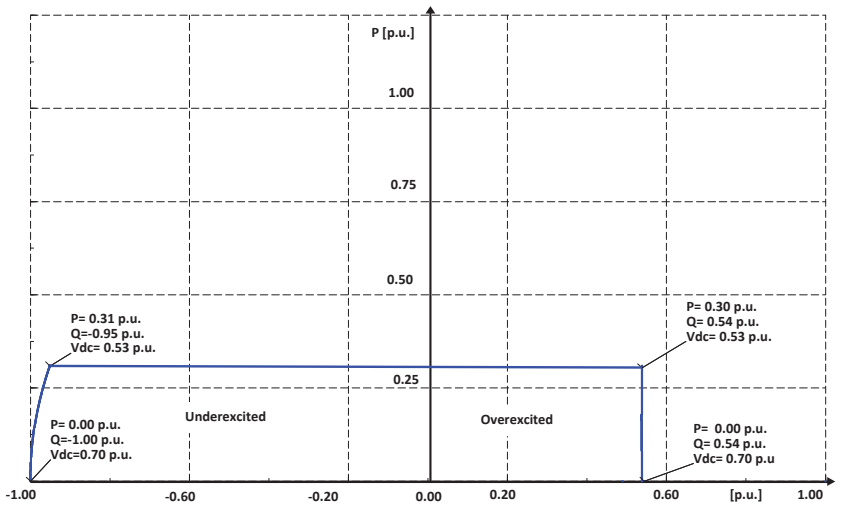

(c)

Figure 14: $\mathrm{PQ}$ capability analysis of the PV generator $\left(\mathrm{G}=400 \mathrm{~W} / \mathrm{m}^{2}\right)$ for a variable $V_{d c}$ (a) $\mathrm{Ta}=10{ }^{\circ} \mathrm{C}(\mathrm{b}) \mathrm{Ta}=20{ }^{\circ} \mathrm{C}(\mathrm{c}) \mathrm{Ta}=40{ }^{\circ} \mathrm{C}$ 


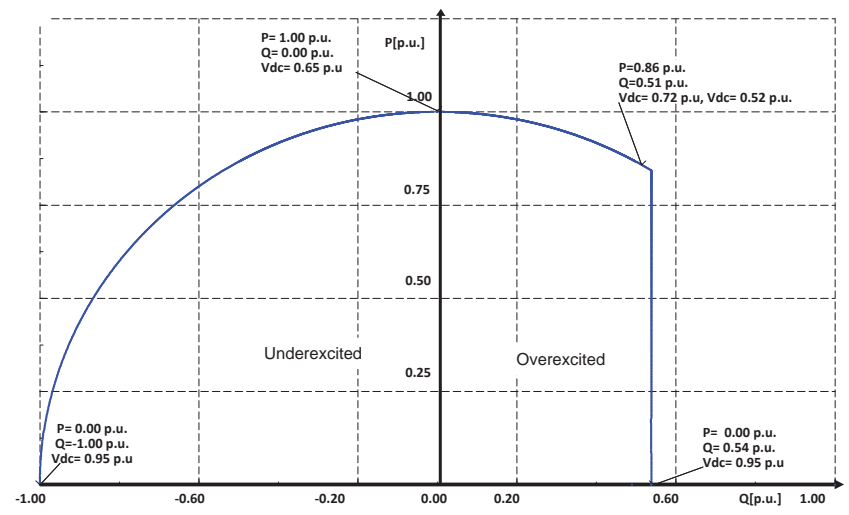

(a)

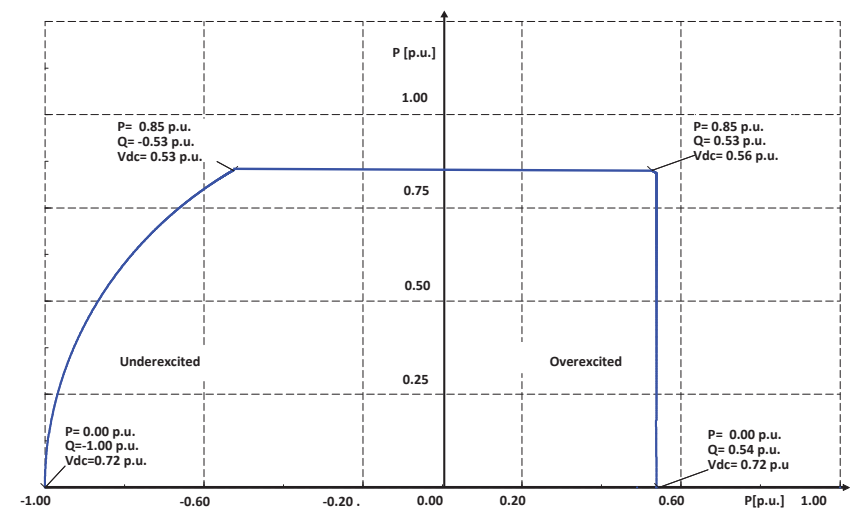

(b)

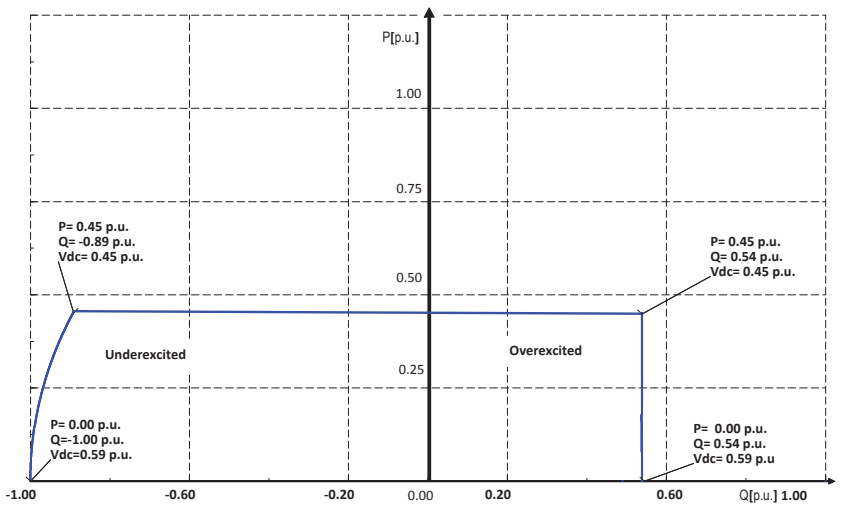

(c)

Figure 15: $\mathrm{PQ}$ capability analysis of the PV generator $\left(\mathrm{G}=1000 \mathrm{~W} / \mathrm{m}^{2}\right)$ for a variable $V_{d c}$ (a) $\mathrm{Ta}=10{ }^{\circ} \mathrm{C}(\mathrm{b}) \mathrm{Ta}=20{ }^{\circ} \mathrm{C}(\mathrm{c}) \mathrm{Ta}=40{ }^{\circ} \mathrm{C}$. 


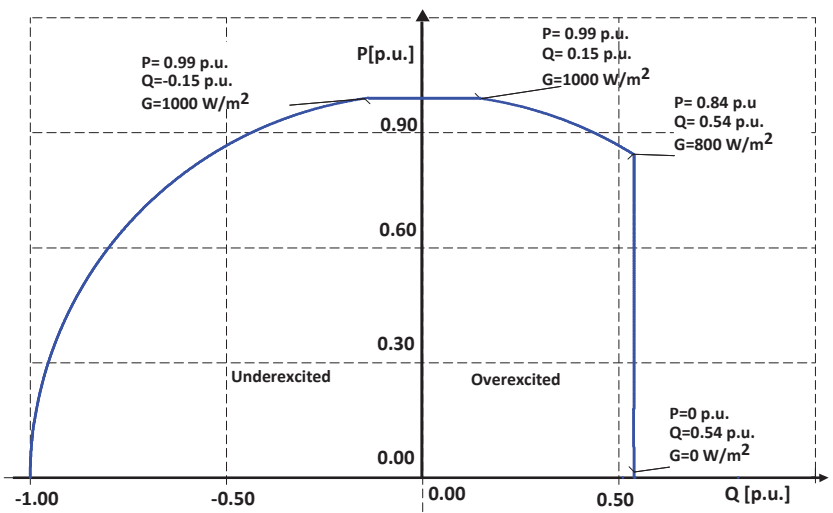

(a)

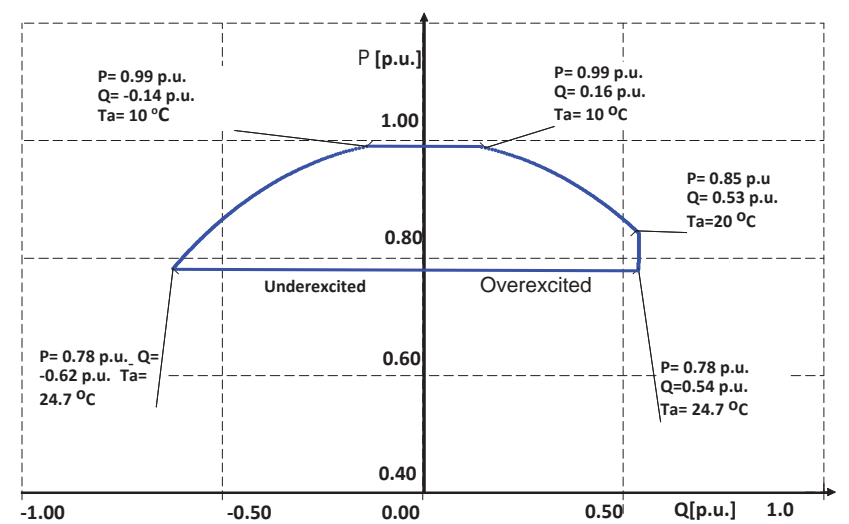

(b)

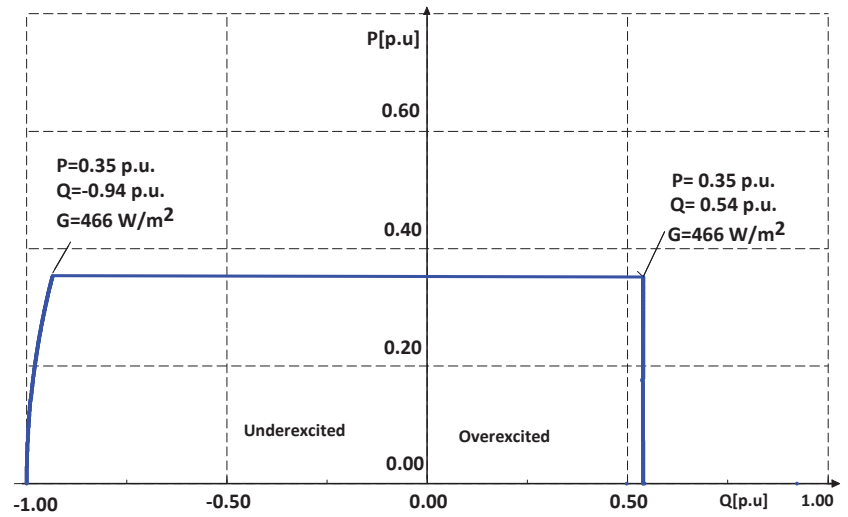

(c)

Figure 16: PQ capability analysis of the PV generator when $V_{d c}=v_{m p p}$ (a) $G=0$ to 1000 $\mathrm{W} / \mathrm{m}^{2}, T_{a}=10{ }^{\circ} \mathrm{C}$ (b) $T_{a}=10$ to $40{ }^{\circ} \mathrm{C}, G=1000 \mathrm{~W} / \mathrm{m}^{2}$ (c) $G=0$ to $1000 \mathrm{~W} / \mathrm{m}^{2}, T_{a}=40$ ${ }^{\circ} \mathrm{C}$ 


\subsection{Variation of the modulation index}

265 solar irradiance and temperature. The scenarios analysed considers the variation of solar irradiance, temperature and modulation index. In each scenario the step size of the modulation index variation is 0.01 and it varies from 0.5 to 1.5 . For these scenarios, the PQ curve is illustrated in Figure 17.

\section{Conclusions}

275 ering the variation of solar irradiance, temperature as well as some electrical characteristics such as the dc voltage and the modulation index. Figures 11 to 13 summarize these curves. For this purpose, the current paper has presented the corresponding mathematical model of the PV array and the PV inverter. the PV generator where Figure 6 was presented. Finally, a validation study was conducted in DIgSILENT PowerFactory ${ }^{\circledR}$ where the complete model has been introduced and simulated under different conditions. From the mathematical analysis and the simulation some conclusions are discussed. parameters: solar irradiance, temperature, dc voltage and the modulation index. These values are dependent on each other in order to obtain the complete PQ curve. In the case where the dc voltage is equal to a single value, the active power and the reactive power will depend mainly on the solar irradiance, temperature 290 and modulation index. But in the case the dc voltage is variable, the complete curve can be obtained for a single solar irradiance and temperature. 


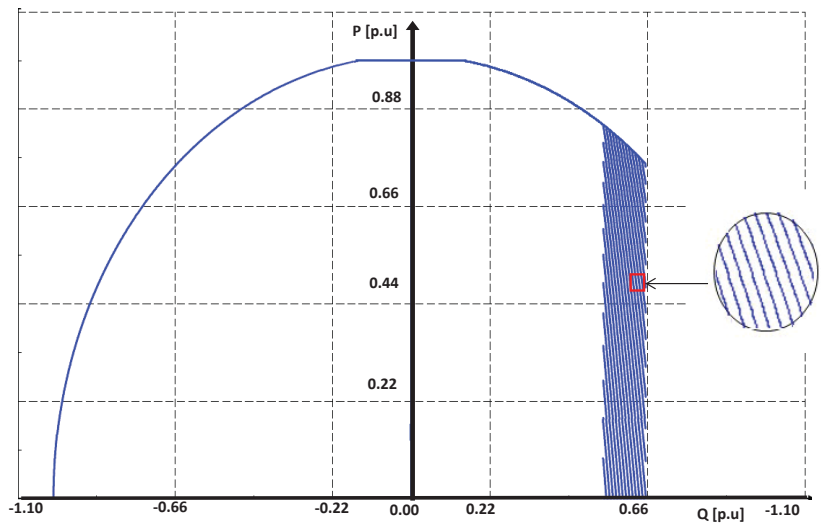

(a)

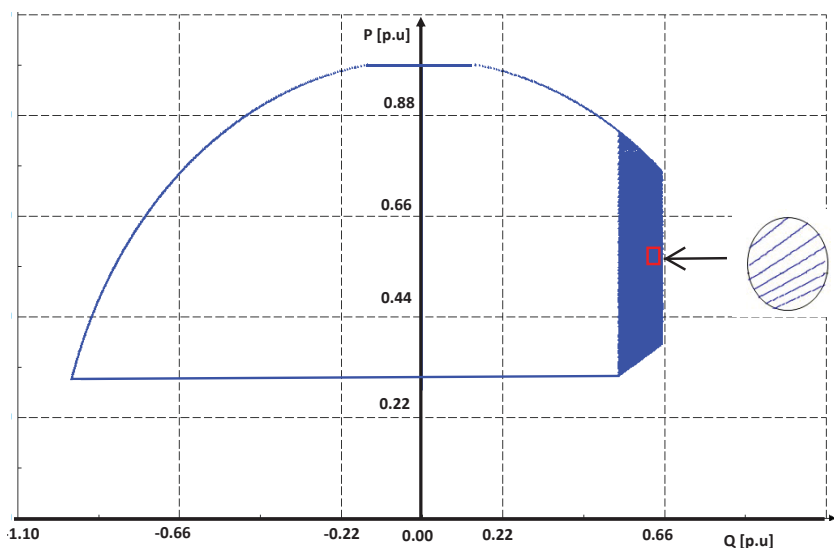

(b)

Figure 17: $\mathrm{PQ}$ capability analysis of the PV generator for a variable modulation index (a) $G=0$ to $1000 \mathrm{~W} / \mathrm{m}^{2}, T_{a}=10{ }^{\circ} \mathrm{C}$ (b) $T_{a}=10$ to $70{ }^{\circ} \mathrm{C}, G=1000 \mathrm{~W} / \mathrm{m}^{2}$. 
The solar irradiance and the temperature are important parameters to identify the SOA of the PV inverter. First, the highest solar irradiance and the lowest temperature determine the highest active power that the PV inverter can supply to the grid. It is necessary to mention that the highest temperature limits the output active power that the PV generator can supply to the system.

The dc voltage and the modulation index are also parameters that affects to the PQ capability curve and the operation of the PV inverter. In this paper, it has been shown that the dc voltage can vary between $v_{\min }$ and $v_{\max }$. The first value depends on the ac voltage value at the output of the PV inverter and the modulation index. The second value depends specifically on the highest solar radiation and the lowest temperature.

In the case that the dc voltage chosen is equal to $v_{m p p}$, the maximum active power can be obtained for a determined solar irradiance and temperature. However, this single point of operation does not permit the PV inverter to work in all of the PQ curve at any moment. Only a variation of solar radiation will permit the change of point of operation. This characteristic is not desirable in LS-PVPP as it is necessary to provide ancillary services to the system.

In overexcited operation, the limits of reactive power depend more on the modulation index than the solar irradiance or temperature. But it continues to depend on the dc voltage. Thus, its drastic variation could affect to the ac voltage at the PV inverter terminals. The control should consider these limitations to vary the modulation index together with the reactive power.

\section{Acknowledgements}

This work has been funded by the National Department of Higher Education, Science, Technology and Innovation of Ecuador (SENESCYT) and by the Spanish Ministry of Economy and Competitiveness under the project ENE201567048-C4-1-R. 


\section{References}

320 [1] A. Cabrera-Tobar, E. Bullich-Massagué, M. Aragüés-Peñalba, O. Gomis-

n Bellmunt, Review of advanced grid requirements for the integration of large scale photovoltaic power plants in the transmission system, Renew. Sustain. Energy Rev. 62 (2016) 971-987. doi:10.1016/j.rser.2016.05.044

口

URL http://www.sciencedirect.com/science/article/pii/

325 S136403211630154X

[2] A. Ellis, R. Nelson, E. Von Engeln, J. MacDowell, L. Casey, E. Seymour,

W. Peter, Reactive power performance requirements for wind and solar plants, in: 2012 IEEE Power Energy Soc. Gen. Meet., IEEE, San Diego, 2012, pp. 1-8. doi:10.1109/PESGM.2012.6345568.

330 \ URL http://ieeexplore.ieee.org/lpdocs/epic03/wrapper.htm? arnumber $=6345568$

[3] R. Albarracin, M. Alonso, Photovoltaic reactive power limits, in: 2013 12th Int. Conf. Environ. Electr. Eng., IEEE, 2013, pp. 13-18. doi:10.1109/EEEIC.2013.6549630.

335 u URL http://ieeexplore.ieee.org/lpdocs/epic03/wrapper.htm? arnumber $=6549630$

[4] F. Delfino, G. Denegri, M. Invernizzi, R. Procopio, G. Ronda, A P-Q capability chart approach to characterize grid connected PV-units (2009).

[5] A. Cabrera-Tobar, E. Bullich-Massagué, M. Aragüés-Peñalba, O. GomisBellmunt, Topologies for large scale photovoltaic power plants, Renew. Sustain. Energy Rev. 59 (2016) 309-319. doi:10.1016/j.rser.2015.12.362.

(1) URL http://www.sciencedirect.com/science/article/pii/ S1364032116000289

[6] T. Markvart, Practical Handbook of Photovoltaics, Elsevier, 2012. doi:10.1016/B978-0-12-385934-1.00020-9.

a URL http://www.sciencedirect.com/science/article/pii/ B9780123859341000209 
[7] A. K. Cabrera, H. U. Banna, C. Koch-Ciobotarus, S. Ghosh, Optimization

n of an air conditioning unit according to renewable energy availability and 350 user's comfort, in: IEEE PES Innov. Smart Grid Technol. Eur., IEEE, Istanbul, 2014, pp. 1-7. doi:10.1109/ISGTEurope. 2014.7028866.

a URL http://ieeexplore.ieee.org/lpdocs/epic03/wrapper.htm? arnumber $=7028866$

[8] B. Marion, Comparison of predictive models for photovoltaic module performance, in: 2008 33rd IEEE Photovolatic Spec. Conf., IEEE, 2008, pp. 1-6. doi:10.1109/PVSC.2008.4922586.

प URL http://ieeexplore.iee.org/articleDetails.jsp?arnumber= 4922586 